\section{Impact of Kiestra total laboratory automation workflow on job satisfaction, education and quality: a staff survey}

To the Editor,

Instruments for automation of sample processing have recently been implemented in the microbiology laboratory. Several studies have demonstrated that automated sample inoculation and incubation may improve microbiological endpoints (such as colony recovery and isolation) compared to manual inoculation, which is likely to improve standardisation and workflow and to decrease workload. ${ }^{1-6}$ In one study, staff found that the plates inoculated with the BD InoqulA instrument were more easy to read. ${ }^{4}$ More recent studies have also demonstrated potential for clinical benefits such as shortened time to results, ${ }^{7-10}$ increased sensitivity for more fastidious organisms, ${ }^{11}$ increased productivity and decreased costs. ${ }^{9}$

Laboratory workflow can have a major impact on efficiency, quality and staff satisfaction. In view of the relative recency of implementation of total laboratory automation (TLA) in microbiology laboratories, there is currently a paucity of information on the impact of various workflows. Few if any studies have evaluated the impact of TLA implementation and the various workflows possible with TLA on staff job satisfaction and staff perception of its effect on professional development, education and result quality. After implementing a change to workflow of Kiestra TLA from the unidirectional workflow, suggested by the manufacturer, we surveyed our microbiology staff to investigate the effect of the change on staff job satisfaction and potential to impact staff education and result quality.

The Monash Health Microbiology Laboratory is a 24-hour laboratory that services outpatients and a large healthcare network with over 2000 acute and sub-acute inpatient beds in Victoria, Australia. In June 2015, Kiestra TLA (BD, The Netherlands) was implemented in our microbiology laboratory. The initial implemented workflow was as suggested by the manufacturer: briefly, a scientist ('reader') would read the culture results from the TLA image and electronically mark which colonies were to be sent for matrix assisted laser desorption/ionisation - time of flight mass spectrometry (MALDI-TOF MS) identification. MALDI-TOF MS results would be returned to a different scientist ('MALDI boss') who was allocated to a bench dedicated to receiving and accepting the MALDI-TOF MS results (or rejecting the results if they were not consistent with the colony morphology). In January 2017, we implemented a workflow change where MALDI-TOF MS results were returned to the scientist that initially read the culture plates rather than to a different scientist (Fig. 1).

We designed a survey, the wording of which was reviewed for clarity and potential bias by the principal scientist in our biochemistry department who had previously completed a survey design course. After suggested amendments were made, in March 2021 a link to an anonymous survey [conducted electronically via SurveyMonkey (Momentive, USA)] was emailed to all microbiology scientific staff in our laboratory. Staff were given two weeks to complete the survey. Scientists replying to the survey were blinded to the question design process, and informed that their responses would remain anonymous and were being sought for the purposes of research and quality improvement.

The six survey questions and possible answers are listed in Fig. 2.

Overall, 38 scientists who worked in the bacteriology section of the laboratory were invited to participate in the survey. Responses were received from 30 (79\%) of the scientists, 18 of whom worked as microbiology scientists prior to implementation of Kiestra TLA. Of these 18, eight stated that their job satisfaction had improved since implementation of Kiestra TLA, for seven it was worse and for three staff job satisfaction was about the same. The majority (16/18) of these scientists thought their job satisfaction improved when TLA workflow was changed so that MALDI-TOF MS results would come back (from the MALDI-TOF MS spotter) to the reader of that specimen rather than going to the 'MALDI boss' and one staff member's job satisfaction was reportedly worse. All 18 of these scientists thought the current workflow of following up one's own MALDI-TOF MS result positively impacted on continuing professional development/education, and 14/18 stated that following up one's own MALDI-TOF MS result positively impacted on quality and reduction of errors, compared to previous workflow when results went to the 'MALDI boss'.

Free text responses to question six of the survey requesting suggestions to improve TLA workflow identified potential bottlenecks to efficiency of requirement for more readers, one more MALDI-TOF MS spotter, and timing of performing Kiestra maintenance.

In summary, we found that the vast majority of the staff (89\%) thought their job satisfaction improved when TLA workflow was changed so that organism identification results would come back to the specimen reader. All staff responding thought the new workflow positively impacted on continuing professional development and education compared to the previous workflow. Over three quarters of scientists stated that following up one's own result positively impacts on quality and reduction of errors compared to the unidirectional TLA workflow.

Our laboratory was the first clinical microbiology laboratory in Australia to implement Kiestra TLA and therefore our staff were not able to see the instrument in advance or discuss the technology with local colleagues. Therefore understandably, prior to the implementation of Kiestra TLA in our laboratory, as anticipated, several staff were sceptical of the benefits and fearful of potential job redundancies that might ensue as a result of this new technology potentially 'taking over' their work. In anticipation of this we implemented several change management sessions with staff where they were given the opportunity to voice their queries and concerns. Despite this, within 6 months of Kiestra implementation, members of the microbiology leadership team sensed a possible gradual drop in morale with several staff commenting that the existing workflow was 'factory-like'. Furthermore, since senior staff tended to be rostered to the 'MALDI boss' bench, the junior staff were not benefitting 


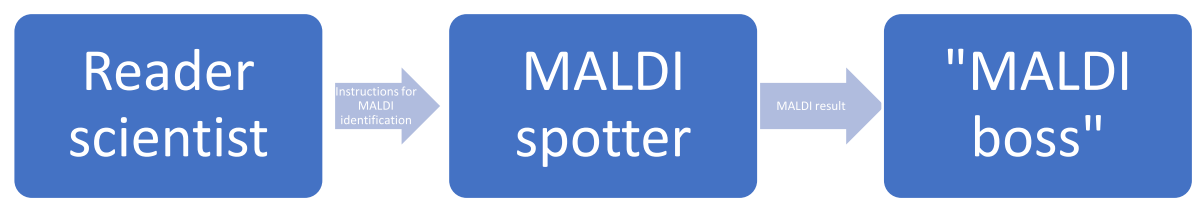

New workflow implemented January 2017:

\section{Reader \\ scientist}

\section{MALDI \\ spotter}

Fig. 1 Two different TLA workflows studied.

Q1. Have you worked as a Microbiology Scientist prior to implementation of Kiestra ${ }^{\text {TM }}$ TLA? If answer is No then you do not need to proceed further with the survey.

\begin{tabular}{|l|l|l|l|l|l|l|l|l|l|}
\hline \multicolumn{10}{|l|}{ Yes 18} \\
\hline \multicolumn{2}{|l|}{ Q2. Do you think your job satisfaction has changed since implementation of Kiestra ${ }^{\text {TM }}$ TLA? } \\
\hline $\begin{array}{l}\text { Much } \\
\text { better 1 }\end{array}$ & Better 7 & $\begin{array}{l}\text { About } \\
\text { the } \\
\text { same 3 }\end{array}$ & Worse 7 & $\begin{array}{l}\text { Much } \\
\text { worse 0 }\end{array}$ & $\begin{array}{l}\text { Much } \\
\text { better 0 }\end{array}$ & Better 0 & $\begin{array}{l}\text { About } \\
\text { the } \\
\text { same 1 }\end{array}$ & Worse 2 & $\begin{array}{l}\text { Much } \\
\text { worse 0 }\end{array}$ \\
\hline
\end{tabular}

Q3. Do you think your job satisfaction changed when TLA workflow was changed so that MALDI results would come back (from the MALDI spotter) to the reader of that specimen rather than going to the MALDI boss?

\begin{tabular}{|l|l|l|l|l|l|l|l|l|l|}
\hline $\begin{array}{l}\text { Much } \\
\text { better } \\
12\end{array}$ & Better 4 & $\begin{array}{l}\text { About } \\
\text { the } \\
\text { same 1 }\end{array}$ & Worse 1 & $\begin{array}{l}\text { Much } \\
\text { worse 0 }\end{array}$ & $\begin{array}{l}\text { Much } \\
\text { better 1 }\end{array}$ & Better 2 & $\begin{array}{l}\text { About } \\
\text { the } \\
\text { same 0 }\end{array}$ & Worse 0 & $\begin{array}{l}\text { Much } \\
\text { worse 0 }\end{array}$ \\
\hline
\end{tabular}

Q4. Do you think the current workflow of following up one's own MALDI result impacts on continuing professional development/education compared to previous workflow when result went to MALDI boss?

\begin{tabular}{|l|l|l|l|l|l|l|l|l|l|}
\hline $\begin{array}{l}\text { Much } \\
\text { better } \\
14\end{array}$ & Better 4 & $\begin{array}{l}\text { About } \\
\text { the } \\
\text { same 0 }\end{array}$ & Worse 0 & $\begin{array}{l}\text { Much } \\
\text { worse 0 }\end{array}$ & $\begin{array}{l}\text { Much } \\
\text { better 1 }\end{array}$ & Better 2 & $\begin{array}{l}\text { About } \\
\text { the } \\
\text { same 0 }\end{array}$ & Worse 0 & $\begin{array}{l}\text { Much } \\
\text { worse 0 }\end{array}$ \\
\hline
\end{tabular}

Q5. Do you think the current workflow of following up one's own MALDI result impacts on quality and reduction of errors compared to previous workflow when result went to MALDI boss?

\begin{tabular}{|l|l|l|l|l|l|l|l|l|l|}
\hline $\begin{array}{l}\text { Much } \\
\text { better } \\
12\end{array}$ & Better 2 & $\begin{array}{l}\text { About } \\
\text { the } \\
\text { same 2 }\end{array}$ & Worse 2 & $\begin{array}{l}\text { Much } \\
\text { worse 0 }\end{array}$ & $\begin{array}{l}\text { Much } \\
\text { better 0 }\end{array}$ & Better 3 & $\begin{array}{l}\text { About } \\
\text { the } \\
\text { same 0 }\end{array}$ & Worse 0 & $\begin{array}{l}\text { Much } \\
\text { worse 0 }\end{array}$ \\
\hline
\end{tabular}

Q6. Please suggest any other Kiestra ${ }^{\mathrm{TM}}$ TLA workflow ideas that you think might improve your job satisfaction. Responses relating to TLA workflow are summarised here:

'More readers.'

'Having a 2nd staff performing MALDI as always waiting for results.'

'By reviewing one's own MALDI mark-up there is continual learning and experience gained when you get to review the actual result/identification. This is very important for development of plate reading skills and awareness. This is particularly important for staff with minimal plate reading experience. Without following up their own work they cannot learn to recognise the bugs... A very satisfying part of our job is when you have worked on a sample \& even from the gram recognised a possible pathogen, read the culture \& determined the presence of what was suspected $\&$ then followed the report thru to completion with sensis. It also makes us feel we are making a different to a patient \& not just part of a 'factory' type pathology work environment without seeing overall outcomes.'

'Maintenance to be done overnight so morning workflow is not interrupted.' (sic)

Fig. 2 Survey questions and responses. Grey shaded responses on right side represent replies from survey respondents who answered 'no' to the first question but still proceeded with the survey. 
from the learning that is a consequence of receiving MALDITOF MS results back to either confirm or refute the scientists' suspected identification based on the colony morphology. In addition, staff described a loss of professional satisfaction when feeling 'disconnected' from the process of following a specimen through from beginning to the end.

Importantly, with respect to quality improvement, staff described that the process of following up one's own work was more likely to reduce errors since receiving back an unexpected MALDI-TOF MS result was a trigger to consider whether the wrong colony might have been spotted onto the MALDI-TOF MS target, whether the culture was mixed or whether the inoculum was misplaced onto an incorrect spot on the MALDI-TOF MS target as has been described in Public Health England UK Microbiology standards. ${ }^{12}$ This impression was supported by findings from this survey conducted after the change of TLA workflow. Further studies could support our findings by including error audits before and after TLA workflow changes.

Limitations of our study include the assessment of contributing factors to job satisfaction particularly in question two, as it is not clear if the reason for the change in job satisfaction was due to the Kiestra TLA or due to other factors or changes in the laboratory that occurred during the same time period. Given that other responses (to questions three, four and five) indicate Kiestra TLA workflow changes were mostly associated with 'much better' outcomes, this implies that lack of change in job satisfaction overall is likely due to factors unrelated to the TLA. In addition, the wording of question one may have selected more experienced staff to respond to the survey: since the impact of laboratory changes may be different for more recently qualified staff as compared to experienced staff, further studies are required to explore this possibility. Further studies are warranted to examine the objective impact of TLA workflow changes on quality metric such as turnaround time and error rates.

In conclusion, after implementing a change to Kiestra TLA workflow we found that job satisfaction improved for the vast majority of the staff. This change was associated with a perceived positive impact on continuing professional development and education and on quality and reduction of errors compared to the unidirectional TLA workflow. Microbiology laboratory managers should be aware of the impact of various TLA workflows on their staff as this is likely to contribute to quality improvement.

Acknowledgements: We thank George Streitberg from Monash Health Biochemistry for reviewing and providing advice on the design and wording of the survey questions.

Conflicts of interest and sources of funding: The authors state that there are no conflicts of interest to disclose.

\section{Maryza Graham ${ }^{1,2,3}$, Emma Lee ${ }^{1}$, Richard Streitberg ${ }^{1}$, John Hamblin ${ }^{1}$, Beena Kumar ${ }^{4}$, Tony M. Korman ${ }^{1,2,3}$,}

${ }^{1}$ Department of Microbiology, Monash Health Pathology, Monash Health, Clayton, Vic, Australia; ${ }^{2}$ Monash Infectious Diseases, Monash Health, Clayton, Vic, Australia; ${ }^{3}$ Faculty of Medicine, Nursing and Health Sciences, Monash University, Clayton, Vic, Australia; ${ }^{4}$ Monash Health Pathology, Monash Health, Clayton, Vic, Australia
Contact Dr Maryza Graham.

E-mail: Maryza.Graham@monashhealth.org

1. Froment P, Marchandin H, Vande Perre P, et al. Automated versus manual sample inoculations in routine clinical microbiology: a performance evaluation of the fully automated InoqulA instrument. $J$ Clin Microbiol 2014; 52: 796-802.

2. Mutters NT, Hodiamont CJ, de Jong MD, et al. Performance of Kiestra total laboratory automation combined with MS in clinical microbiology practice. Ann Lab Med 2014; 34: 111-7.

3. Croxatto A, Dijkstra K, Prod'hom G, et al. Comparison of inoculation with the InoqulA and WASP automated systems with manual inoculation. J Clin Microbiol 2015; 53: 2298-307.

4. Strauss S, Bourbeau PP. Impact of introduction of the BD Kiestra InoqulA on urine culture results in a hospital clinical microbiology laboratory. J Clin Microbiol 2015; 53: 1736-40.

5. Jacot D, Sarton-Lohéac G, Coste AT, et al. Performance evaluation of the becton dickinson Kiestra ${ }^{\mathrm{TM}}$ IdentifA/SusceptA. Clin Microbiol Infect 2021 Aug; 27: 1167.e9-17.

6. Croxatto A, Prod'hom G, Faverjon F, et al. Laboratory automation in clinical bacteriology: what system to choose? Clin Microbiol Infect 2016; 22: 217-35.

7. Graham M, Tilson L, Streitberg R, et al. Improved standardization and potential for shortened time to results with BD Kiestra ${ }^{\mathrm{TM}}$ total laboratory automation of early urine cultures: a prospective comparison with manual processing. Diagn Microbiol Infect Dis 2016; 86: 1-4.

8. Yarbrough ML, Lainhart W, McMullen AR, et al. Impact of total laboratory automation on workflow and specimen processing time for culture of urine specimens. Eur J Clin Microbiol Infect Dis 2018; 37: 2405-11.

9. Culbreath K, Piwonka H, Korver J, et al. Benefits derived from full laboratory automation in microbiology: a tale of four laboratories. $J$ Clin Microbiol 2021; 59: e01969-20.

10. Dauwalder O, Landrieve L, Laurent F, et al. Does bacteriology laboratory automation reduce time to results and increase quality management? Clin Microbiol Infect 2016; 22: 236-43.

11. Klein S, Nurjadi D, Horner S, et al. Significant increase in cultivation of Gardnerella vaginalis, Alloscardovia omnicolens, Actinotignum schaalii, and Actinomyces spp. in urine samples with total laboratory automation. Eur J Clin Microbiol Infect Dis 2018; 37: 1305-11.

12. Public Health England. UK Standards for Microbiology Investigations: Matrix-Assisted Laser Desorption/Ionisation - Time of Flight Mas Spectrometry (MALDI-TOF MS) Test Procedure. TP 40 Issue 1.1. London: Public Health England, 2019. https://www.gov.uk/government/ publications/smi-tp-40-maldi-tof-ms-test-procedure

DOI: https://doi.org/10.1016/j.pathol.2021.10.010

\section{Invasive extended-spectrum beta- lactamase (ESBL) related infection rates are not influenced by international travel restrictions}

To the Editor,

Escalating antimicrobial resistance (AMR) is recognised by the World Health Organization and World Economic Forum as a major global health and security threat, with supply of new drugs vastly outstripped by the rate of resistance development. Global rates of extended spectrum betalactamase (ESBL) carriage in healthy populations have risen 8 -fold to $21 \%$ over the last 15 years, ${ }^{1}$ and recent estimates suggest that 700,000 deaths per year are attributable to AMR worldwide. ${ }^{2}$ Increasing resistance profiles amongst Gram negative bacteria are of particular clinical concern due to the limited repertoire of antibiotics that are effective against these organisms and their ability to readily exchange drug resistance elements through horizontal gene transfer. ${ }^{3}$ Key factors driving high resistance rates include 